\title{
Copper ions regulate cytotoxicity of disulfiram to myeloid leukemia cells
}

\author{
JARMILA NAVRÁTILOVÁ ${ }^{1}$, PAVLA JUNGOVÁ ${ }^{2}$, PETR VANHARA ${ }^{1}$, \\ JAN PREISLER $^{1,2}$, VIKTOR KANICKY ${ }^{2}$ and JAN SMARDA ${ }^{1}$ \\ ${ }^{1}$ Department of Experimental Biology, ${ }^{2}$ Department of Chemistry, \\ Faculty of Science, Masaryk University, Brno, Czech Republic
}

Received June 18, 2009; Accepted August 14, 2009

DOI: 10.3892/ijmm_00000277

\begin{abstract}
White blood cell (WBC) count is considered a prognostic risk factor in acute myeloid leukemia. As density of leukemic cells increases, the cytotoxic activity of certain anticancer drugs, such as vincristine and doxorubicin, progressively decreases. In this study, we investigated the cell density-dependent induction of apoptosis of human acute myeloid leukemia U937 and ML-1 cells by disulfiram (DSF), the dithiocarbamate drug recently proposed for treatment of human cancers. This effect is dependent on uptake of extracellular copper and its intracellular accumulation. Highdensity cells cannot uptake and accumulate this metal to a sufficient level that would allow induction of apoptosis due to progressive decrease of its extracellular concentration. Simple addition of copper can resume sensitivity of highdensity leukemic cells to DSF and improve efficiency of antileukemic therapies using this drug, thus providing benefit to patients with high WBC count.
\end{abstract}

\section{Introduction}

White blood cell (WBC) count can significantly affect outcome of leukemias and is generally accepted as a significant prognostic factor for acute lymphoid (ALL) and acute myeloid (AML) leukemias $(1,2)$. Interindividual variations in WBC count at diagnosis are common, ranging from leukopenia to more than 400 million cells $/ \mathrm{ml}$ blood. The WBC count can significantly affect efficacy of chemotherapy because cytotoxicity of chemotherapeutics, such as daunorubicin, doxorubicin, vincristine, tamoxifen and paclitaxel, rapidly decreases in cultures of high density (3-7). Several explanations of this phenomenon have been suggested. First,

Correspondence to: Professor Jan Smarda, Department of Experimental Biology, Faculty of Science, Masaryk University, Kotlárská 2, 61137 Brno, Czech Republic

E-mail: smarda@sci.muni.cz

Key words: disulfiram, copper, myeloid leukemia, cell density, inoculum effect, SALD ICP MS intracellular accumulation of the drug is low in cells growing at high density. This inoculum effect was reported especially for drugs with large capacity to be taken up and stored by leukemic cells, such as daunorubicin, and the drugs with multiple cellular binding sites, such as vincristine. Thus, cells growing at high densities accumulate the drug to such an extent that the growth media is depleted of the drug (3). Second, cell density can affect frequency of cell-cell interactions. In dense cell cultures of AML, the membrane-bound growth factors can mediate frequent cell-cell interactions, thus preventing apoptosis from occuring (8). Third, increased cell density can induce the log to plateau cell growth transition that makes cells drug-resistant. This effect results from activation of proteins associated with the drug resistance in a cell cycle-dependent and proliferation-dependent manner (9).

Disulfiram (DSF), the dithiocarbamate drug capable of inhibiting alcohol dehydrogenase, has been used for treatment of alcoholism for decades. Due to this long clinical experience, data concerning its hepatotoxicity, adverse effects on central nervous system, neuropathology and safe concentrations in human body are available (10). Importantly, DSF in safe concentrations possesses anti-cancer effects. It is selectively cytotoxic to cells of chronic lymphoid leukemia, melanoma and breast carcinoma, leaving non-cancer cells unaffected (11-14). The tumor suppressive effects of DSF often depend on passive cellular uptake of this drug in complexes with copper. Copper ions were shown to be involved in regulation of dithiocarbamate-induced apoptosis of thymocytes, prostate cancer cells, astrocytes and melanoma cells $(12,13,15-18)$. Recently, the copper-mediated inhibition of histone acetyltransferase activity and induction of apoptosis in pyrrolidine dithiocarbamate-treated leukemic cells have also been reported (19).

In previous reports, dithiocarbamates were shown to be effective growth suppressors and apoptosis inducers of cells seeded at low density, while dense cell populations were resistant to these drugs $(20,21)$. The mechanism responsible for this effect that can limit use of dithiocarbamates in anticancer therapies has not been clarified yet. The aim of the present study was to describe the mechanism responsible for cell density-dependent effects of DSF on human myeloid leukemia U937 and ML-1 cells and to identify the factors capable of enhancing its tumor suppressive effects in cells 
growing at high densities. We demonstrate that DSF induces apoptosis in cell density- and copper-dependent manner and in concentrations possessing no adverse effects in vivo. We present rationale of this phenomenon based on the availability of copper ions to cellular uptake. We conclude that it is the limited copper supply that is responsible for the DSF-resistance of myeloid leukemia cells growing at high density. Simple addition of $\mathrm{Cu}^{2+}$ can reverse the insensitivity of dense populations of leukemic cells to DSF and significantly enhance its tumor suppressive effects.

\section{Material and methods}

Cell cultivation. U937 (ATCCT, cat. number CRL-1593.2) and ML-1 cells (gift from Ute Moll) were seeded at low density (LD, 50,000 cells/ml), intermediate density (ID, 100,000 cells $/ \mathrm{ml}$ ) and high density (HD, 200,000 cell $/ \mathrm{ml}$ ) in RPMI-1640 (Sigma-Aldrich, Prague, Czech Republic) supplemented with $10 \%$ FCS (Invitrogen, Paisley, UK), Lglutamine $(2 \mathrm{mM})$, penicillin $(100 \mathrm{U} / \mathrm{ml})$ and streptomycin $(100 \mu \mathrm{g} / \mathrm{ml})$ (Sigma-Aldrich) and cultured in humidified 5\% $\mathrm{CO}_{2}$ atmosphere at $37^{\circ} \mathrm{C}$. In some experiments, U937 cells were cultured in conditioned media CM1 and CM2. To obtain CM1, HD U937 cells growing in complete medium were treated with dimethylsulfoxide (DMSO, Sigma-Aldrich) for $24 \mathrm{~h}$, pelleted by centrifugation $(1750 \mathrm{~g} / 7 \mathrm{~min})$ and discarded. The supernatant was used as CM1. To obtain CM2, the same cells were treated with tetraethylthiuram disulfide disulfiram (DSF) dissolved in DMSO (100 ng/ml, Sigma-Aldrich) for $24 \mathrm{~h}$ and processed similarly as for CM1. Both media exhibited the same $\mathrm{pH}$. The copper-specific cell-impermeable chelator, bathocuproine disulfonic acid, (BCPS, Sigma-Aldrich) was dissolved in $\mathrm{H}_{2} \mathrm{O}$ in $100 \mathrm{mM}$ concentration. N-acetyl-Lcysteine (NAC, Sigma-Aldrich) was dissolved in complete medium to a final concentration of $450 \mathrm{mM}$. $\mathrm{pH}$ of the NAC solution was adjusted to the same value as in cultivation medium. As a source of copper ions for supplementation of media, we used $250 \mu \mathrm{M}$ solution of $\mathrm{CuSO}_{4}$ (Chemapol, a.s., Prague, Czech Republic) in $\mathrm{H}_{2} \mathrm{O}$. Addition of $\mathrm{CuSO}_{4}$ did not affect $\mathrm{pH}$ of the media.

Proliferation, viability and cell cycle analyses. To assess viability, U937 and ML-1 cells were treated with DSF for 24 or $48 \mathrm{~h}$. As a control, the cells were treated with DMSO or left untreated. In all experiments, concentration of DMSO did not exceed $0.14 \%$ and did not affect cell viability. To determine the effects of BCPS, NAC or $\mathrm{CuSO}_{4}$, U937 cells were treated with DSF $(100 \mathrm{ng} / \mathrm{ml})$ in the presence or absence of BCPS $(25 \mu \mathrm{M}), \mathrm{NAC}(5 \mathrm{mM})$ or $\mathrm{CuSO}_{4}(70-200 \mathrm{nM})$ for $24 \mathrm{~h}$. To address cell growth, U937 and ML-1 cells were seeded at LD and HD and cultured for 24 and $48 \mathrm{~h}$. Viable cells were enumerated in hemocytometer by eosin dye exclusion using light microscopy. For cell cycle analyses, the cells were cultured for 24 and $48 \mathrm{~h}$, washed twice with PBS, resuspended in $0.5 \mathrm{ml}$ of PBS, fixed in $4 \mathrm{ml}$ of $70 \%$ ethanol and stored at $4^{\circ} \mathrm{C}$ for $24 \mathrm{~h}$. Fixed cells were centrifuged, washed with PBS and stained in $0.5 \mathrm{ml}$ of Vindelov solution (22) for $30 \mathrm{~min}$ at $37^{\circ} \mathrm{C}$. DNA content in at least $1.5 \times 10^{4}$ cells was determined by a Cytomics FC 500 CXP flow cytometry system (Beckman Coulter, Fullerton, CA, USA).
Gel electrophoresis and immunoblotting. The same number of U937 and ML-1 cells was treated with DSF alone or in combination with $\mathrm{CuSO}_{4}$ for $12 \mathrm{~h}$. As a control, the cells were treated with DMSO alone or in combination with $\mathrm{CuSO}_{4}$ or left untreated. Then, the cells were lysed in SDSloading buffer containing $0.1 \mathrm{M}$ Tris ( $\mathrm{pH} 6.8$ ), 16\% v/v glycerol, $3.2 \% \mathrm{w} / \mathrm{v}$ SDS, $10 \% \mathrm{v} / \mathrm{v}$ ß-mercaptoethanol and $0.005 \% \mathrm{w} / \mathrm{v}$ bromophenol blue. The protein extracts were boiled for $5 \mathrm{~min}$, resolved by $10 \%$ sodium dodecylsulfate polyacrylamide gel electrophoresis (SDS-PAGE) and electroblotted to Immobilon-P membrane (Millipore, Billerica, MA, USA). The blots were probed with the PARP-specific(210-220-R100, Alexis Biochemicals, San Diego, CA, USA) and actin-specific antibodies (A5060, Sigma-Aldrich) according to the manufacturer's instructions. The blots were developed with goat anti-rabbit (A3687, Sigma-Aldrich) secondary antibody (1:15000) conjugated to alkaline phosphatase using 5-bromo-4-chloro-3-indolyl phosphate and nitroblue tetrazolium chromogenic substrates (both purchased from Sigma-Aldrich).

Detection of apoptotic bodies. A total of $1 \times 10^{6} \mathrm{U} 937$ cells were seeded at either low (LD) or high (HD) densities and treated with DSF alone or in combination with $\mathrm{CuSO}_{4}$, DMSO alone or in combination with $\mathrm{CuSO}_{4}$, or left untreated for $12 \mathrm{~h}$. The cells were washed with PBS, pelleted by centrifugation (200 g/5 min), suspended in $500 \mu \mathrm{l}$ of PBS, fixed in $5 \mathrm{ml}$ of the methanol: acetic acid (3:1) fixative and stored at $-20^{\circ} \mathrm{C}$. Next day, the cell were pelleted by centrifugation (200 g/8 min) and suspended in $100 \mu 1$ of the methanol: acetic acid fixative solution; $20 \mu \mathrm{l}$ of the cell suspension was dropped on a slide, allowed to dry and stained with $10 \mu \mathrm{l}$ of propidium iodide $(10 \mu \mathrm{g} / \mathrm{ml})$. Apoptotic bodies were enumerated by visual inspection of at least 200 cells by fluorescence microscopy.

DNA fragmentation analysis. A total of $1 \times 10^{6}$ U937 cells were seeded at either LD or HD conditions and treated with DSF, DMSO or left untreated for $12 \mathrm{~h}$. Genomic DNA was isolated using Invisorb Apoptosis Detection Kit II (Invitek $\mathrm{GmbH}$, Berlin-Buch, Germany), resolved by $1.2 \%$ agarose gel electrophoresis, stained with ethidium bromide and visualised by UV light.

Determination of copper concentration. The cells were seeded at LD and HD and treated with DSF, DMSO or left untreated. To determine the effect of BCPS and NAC, the cells were treated with DSF in the presence or absence of BCPS $(25 \mu \mathrm{M})$ and NAC $(5 \mathrm{mM})$ for $6 \mathrm{~h}$. To determine the effects of CM1 and CM2, the cells were treated with DSF for $6 \mathrm{~h}$ as well. As a control, the cells were treated with DMSO. Pelleted cells were washed twice with $1 \mathrm{X}$ PBS, counted in hemocytometer and lysed in a mixture of $3 \mathrm{~N} \mathrm{HCl}$ and $10 \%$ trichloroacetic acid (12) at room temperature for $3 \mathrm{~h}$ followed by incubation at $70^{\circ} \mathrm{C}$ for $5 \mathrm{~h}$. The lysate was centrifuged (600 g/5 min) to remove cell debris and the total amount of copper in supernatant was determined by substrate-assisted laser desorption inductively-coupled plasma mass spectrometry (SALD ICP MS) (23). Each sample was mixed with $40 \mu \mathrm{M}$ aqueous solution of rhodamine $\mathrm{B}$ in a $1: 3$ volume 


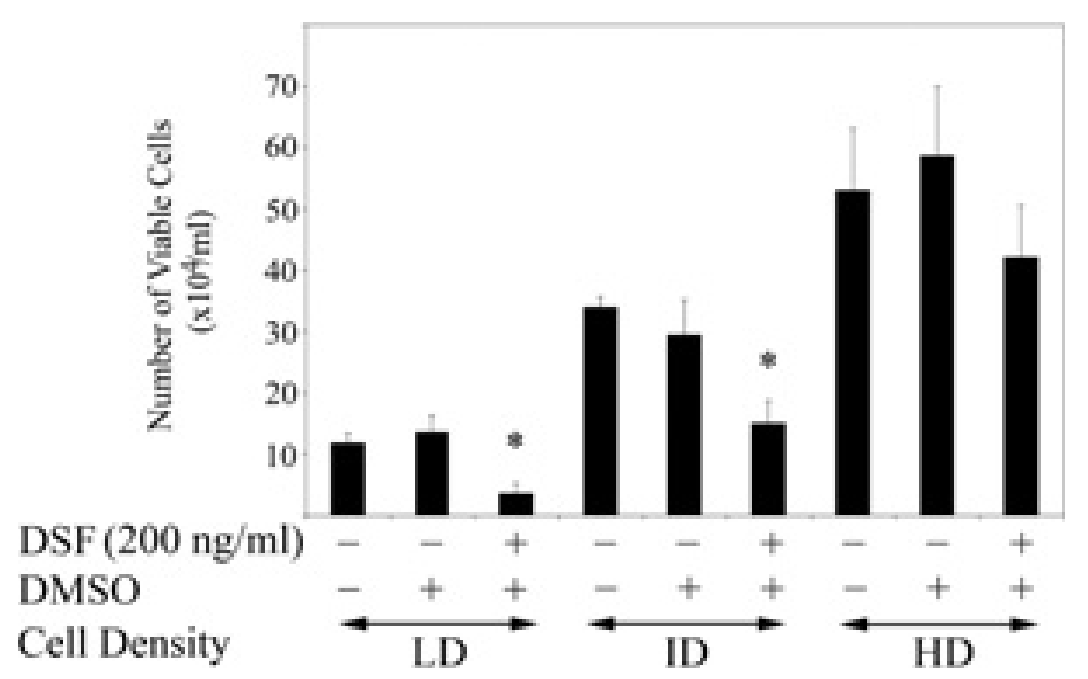

Figure 1. Cytotoxicity of DSF inversely correlates with density of U937 cell populations. U937 cells were seeded at densities 50,000, 100,000 and 200,000 cells/ml (HD), and treated with DSF (200 ng/ml) for $24 \mathrm{~h}$. As a control, the cells were either left untreated or treated with DMSO. The columns indicate total number of viable cells determined by eosin dye exclusion using light microscopy. Error bars indicate standard deviations. Data obtained from at least three independent experiments were processed using Student's t-test. Asterisks indicate significant differences from DSF-treated HD cells ( $\mathrm{p}<0.05$ ) expressed as percentage of DMSO-treated cells.

ratio for spot visualization and spotted onto a polyethylene terephthalate glycol plate as a 200-nl droplet in five replicates. The sample plate was then inserted into an ablation system (model UP 213, New Wave, Fremont, CA), and spots were scanned by a 213-nm laser beam in a zigzag-shaped raster; the laser-beam waist was adjusted to the maximum size $\sim 300 \mu \mathrm{m}$. Size of the raster was selected according to the spot diameter to desorb the entire sample (typical area $\sim 1 \mathrm{~mm}^{2}$ ), and the analysis time of each sample ranged from 30 to $60 \mathrm{sec}$. The ablation cell was flushed with a carrier gas (helium, flow rate $1.0 \mathrm{l} / \mathrm{min}$ ), which transported the aerosol to an ICP mass spectrometer (Agilent, model 7500CE). A sample gas flow of argon was admixed to the helium carrier gas flow subsequent to the laser ablation cell $(0.6 \mathrm{l} / \mathrm{min})$. Optimization of LA ICPMS conditions (gas flow rates, sampling depth, electrostatic lens voltages of the MS) was performed with the glass reference material NIST SRM 612 regarding the maximum signal-to-noise ratio and minimum oxide formation $\left(\mathrm{ThO}^{+} / \mathrm{Th}^{+}\right.$ counts ratio $0.2 \%, \mathrm{U}^{+} / \mathrm{Th}^{+}$counts ratio $1.1 \%$ ). Other ICPMS parameters were adjusted in compliance with the manufacturer's recommendations. The laser fluence was $71 \mathrm{MW} / \mathrm{cm}^{2}$, the repetition rate $10 \mathrm{~Hz}$, and the scan rate $100 \mu \mathrm{m} / \mathrm{s}$. The ions were measured with an integration time $0.1 \mathrm{sec} /$ isotope. Both the flush time and the laser warm-up time were set to $3 \mathrm{sec}$. The ion signal of two copper isotopes, ${ }^{63} \mathrm{Cu}$ and ${ }^{65} \mathrm{Cu}$, was monitored to reveal possible polyatomic interferences of ${ }^{40} \mathrm{Ar}^{25} \mathrm{Mg},{ }^{40} \mathrm{Ar}^{23} \mathrm{Na}$ etc. Signal of the most abundant isotope, ${ }^{63} \mathrm{Cu}$ was used for data evaluation. To determine the level of copper in CM1 and CM2 and the medium obtained from LD U937 cells, the media were prepared as described above and copper contents assessed after appropriate dilution by ICP MS using Babington nebulizer with Scott double-pass spray chamber (Agilent, Japan). Optimization of ICP MS conditions was performed regarding the maximum $\mathrm{S} / \mathrm{N}$ ratio in compliance with the manufacturer's recommendations. Following ICP-MS parameters were used: carrier gas (argon) flow, $0.90 \mathrm{l} / \mathrm{min}$; make-up gas (argon) flow, $0.19 \mathrm{l} / \mathrm{min}$; nebulizer pump flow, $0.022 \mathrm{ml} / \mathrm{s}$ and spray chamber temperature, $2^{\circ} \mathrm{C}$. The ions were measured with an integration time $0.1 \mathrm{sec} /$ isotope; signal of ${ }^{65} \mathrm{Cu}$ was used for data evaluation.

Statistics. Data were processed by analysis of variance followed by Student's t-test.

\section{Results}

Cytotoxicity of DSF to myeloid leukemia cells is cell densitydependent. To examine cytotoxicity of DSF, we seeded U937 cells at low $(50,000$ cells $/ \mathrm{ml})$, intermediate $(100,000$ cells $/ \mathrm{ml})$, and high $(200,000$ cells $/ \mathrm{ml})$ densities and exposed them to $200 \mathrm{ng} / \mathrm{ml} \mathrm{DSF}$ for $24 \mathrm{~h}$. As a control, the cells were treated with the same amount of the DMSO solvent. Then, viable cells were enumerated by eosin dye exclusion using light microscopy. We found that viability of DSF-treated U937 cells seeded at low density (LD) was reduced by $70 \%$, while viability of U937 cells seeded at intermediate density (ID) was reduced by about $50 \%$, and viability of U937 cells seeded at high density (HD) was reduced by only about $21 \%$ (Fig. 1). Similar results were obtained also for ML-1 cells (not shown). This documents that DSF is cytotoxic to human myeloid leukemia cells in cell density-dependent manner.

Decreased sensitivity of dense cell populations to various drugs can result from lower actual concentration of the drug available to individual cells. To investigate how sensitivity of U937 cells growing at different densities depends on actual DSF concentration, the cells were seeded at low and high densities again, exposed to increasing doses of DSF for 1 day before measuring the cell viability. Viability of LD U937 cells was significantly reduced by DSF at 100, 200 and $400 \mathrm{ng} / \mathrm{ml}$ concentrations (Fig. 2). In contrast, viability of HD U937 cells that had been seeded at 4-fold higher density than LD U937 cells was not significantly affected even upon treatment with $1600 \mathrm{ng} / \mathrm{ml}$ DSF (Fig. 2). Again, ML-1 cells behaved similarly as U937 cells (not shown). The fact that even 16-fold 

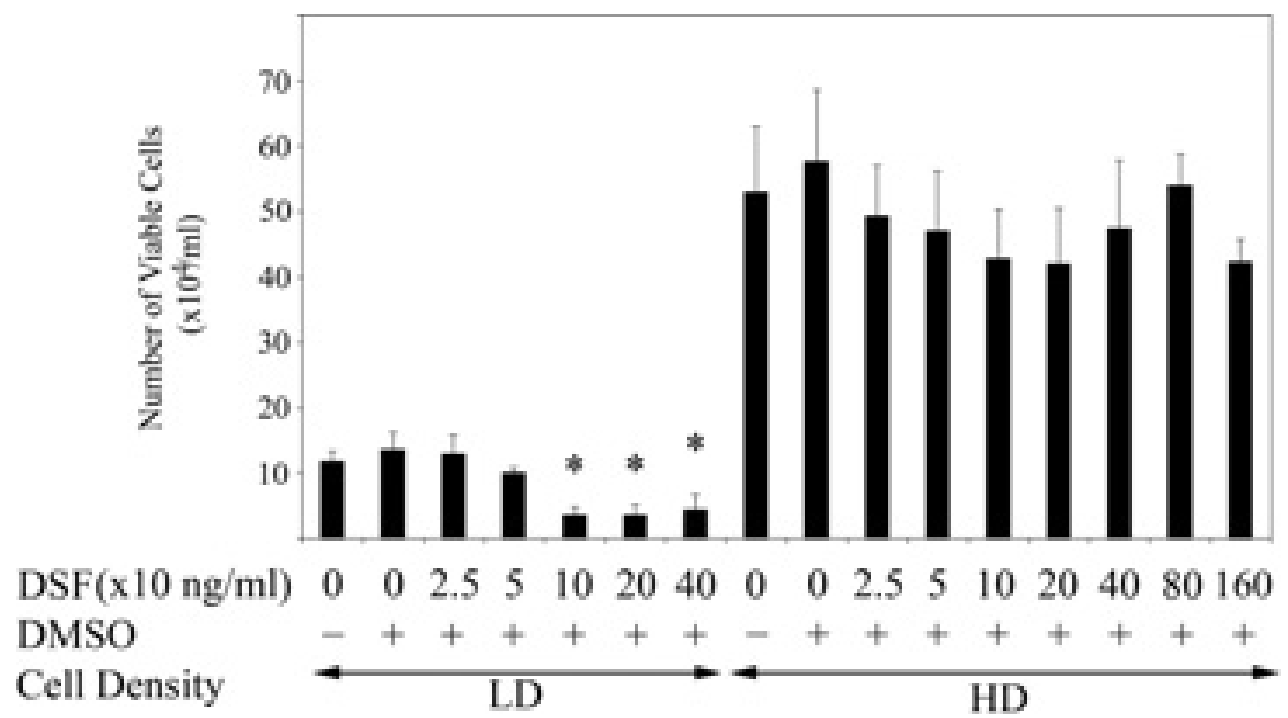

Figure 2. Resistance of HD U937 cells to DSF does not result from low actual concentration of DSF available to individual cells. U937 cells were seeded at densities 50,000 (LD) and 200,000 cells/ml (HD), and treated with DSF at indicated concentrations for $24 \mathrm{~h}$. As a control, the cells were either left untreated or treated with DMSO. The columns indicate total number of viable cells determined by eosin dye exclusion using light microscopy. Data obtained in at least three independent experiments were processed using Student's t-test. Error bars indicate standard deviations. Asterisks indicate significant differences from DSF-treated HD cells $(\mathrm{p}<0.05)$ expressed as percentage of DMSO-treated cells.

excess of DSF fails to reduce viability of myeloid leukemia cells growing at high density to similar level as the same cells growing in low density suggests that it is not the actual low concentration of DSF available to HD cells that permits their growth in the presence of this drug.

To exclude that it is simply lower proliferation capacity that limits sensitivity of cells seeded at higher density to the drug (9), we compared growth rates and cell cycle profiles of LD, ID and HD U937 and ML-1 cells during $48 \mathrm{~h}$. We found that cell density did not limit proliferation rates and left the cell cycle profiles unaffected indeed (not shown).

DSF induces apoptosis of myeloid leukemia cells in cell density-dependent manner. Lower viability of DSF-treated myeloid leukemia cells can result from increased rate of apoptosis. To investigate whether DSF can control programmed cell death, we seeded U937 cells at low $(50,000$ cells $/ \mathrm{ml}$, LD) and high (200,000 cells/ml, HD) densities, and exposed them to DSF for $12 \mathrm{~h}$. Frequency of apoptosis was determined according to the PARP truncation, cell morphology and DNA fragmentation. First, extracts of harvested cells were resolved by SDS-PAGE and immunoblotted using the PARP-specific antibody. The truncated form of PARP with molecular weight of $89 \mathrm{kDa}$ was found in the DSF-treated LD but not HD U937 cells (Fig. 3A) suggesting that only U937 cells growing at low density underwent apoptosis in response to DSF. Second, morphology of fixed DSF-treated LD and HD U937 cells was assessed by staining with propidium iodide and fluorescence microscopy. By visual inspection of at least three hundred LD U937 cells treated with 100 and $200 \mathrm{ng} / \mathrm{ml}$ DSF, we found $45 \%$ of cells exhibiting apoptotic morphology (Fig. 3B). In contrast, only 5\% of HD U937 cells treated with $100 \mathrm{ng} / \mathrm{ml} \mathrm{DSF}$ and $2 \%$ of HD U937 cells treated with $200 \mathrm{ng} / \mathrm{ml}$ DSF underwent apoptosis. Third, DNA fragmentation occuring in DSF-treated LD and HD U937 was assessed by analysis of its electrophoretic mobility. Apoptotic DNA laddering was detected only in DSF-treated LD U937 cells but not in similarly treated HD U937 cells (Fig. 3C). These results document that DSF induces apoptosis of myeloid leukemia cells growing at low but not high densities.

The effects of DSF in myeloid leukemia cells are mediated by factors present in the growth medium. We hypothesized that it is the depletion of the growth medium used for cultivation of HD U937 cells (conditioned medium) of some factor(s) mediating the DSF-induced apoptosis that causes the inoculum effect (3). If this hypothesis is correct, LD U937 cells cultured in the HD U937-conditioned medium should become resistant to DSF to similar extent as HD U937 cells. If the factor(s) present in growth medium is/are not involved in control of DSF cytotoxicity, viability of LD U937 cells was unlikely to be affected by the medium exchange. Therefore, HD U937 cells were cultured either in the presence of DSF or the DMSO control for $24 \mathrm{~h}$. The conditioned media of DMSO-treated cells (CM1) and DSF-treated cells (CM2) were collected. Then, U937 cells were seeded at LD into CM1 and CM2 and treated with DSF for $24 \mathrm{~h}$ before assessing their viability. In contrast with viability of cells in regular media (Fig. 2) and in CM1, viability of LD U937 cells in CM2 was not significantly reduced in the presence of DSF (Fig. 4). ML-1 cells behaved similarly: we detected almost no viable LD ML-1 cells upon stimulation with DSF in CM1, while number of viable cells was decreased only by $6 \%$ in CM2 (not shown). Since it was CM2 that suppressed cytotoxicity of DSF to myeloid leukemia cells, we wished to identify the factors present in/absent from CM2 that were responsible for this effect.

The effects of DSF in myeloid leukemia cells are mediated by the copper ions. As other thiocarbamates, DSF acts as a cell permeable metal-chelator. By increasing intracellular level of copper, DSF induces growth arrest and apoptosis of various 

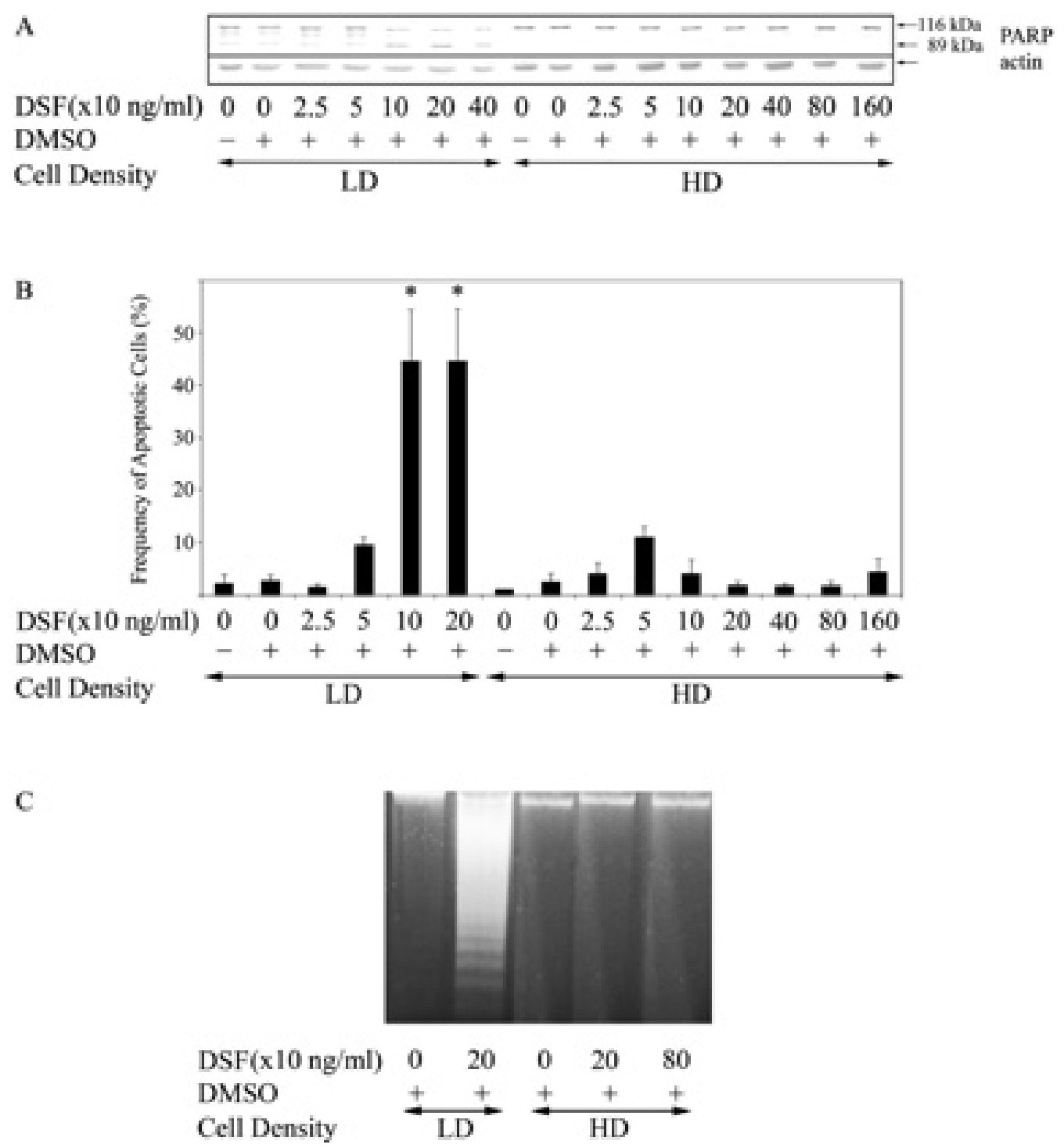

Figure 3. Cell density modifies apoptosis-promoting effect of DSF on U937 cells. U937 cells were seeded as described in the legend of Fig. 2 and treated with DSF at indicated concentrations for $12 \mathrm{~h}$. As a control, the cells were treated with either DMSO solvent or left untreated. Protein extracts from harvested cells were resolved by SDS-PAGE and analysed by immunoblotting using the PARP-specific antibody (upper box) and actin-specific antibody as a control for sample loading (lower box). The blots were developed by alkaline phosphatase-conjugated secondary antibodies and chromogenic substrates (A). The same cells were harvested, fixed and stained with propidium iodide. Morphology of at least 200 cells in each sample was examined by fluorescence microscopy. Columns indicate the average numbers of apoptotic bodies obtained in three independent experiments. Error bars indicate standard deviations. Asterisks indicate significant differences $(\mathrm{p}<0.05)$ from HD cells as determined by Student's t-test $(\mathrm{B})$. Genomic DNA was purified from harved cells, resolved by agarose gel electrophoresis, stained with ethidiumbromide and visualized in UV light as described in Materials and methods (C).

cell types (12) but mechanism of these effects on myeloid cells has not been described yet. To determine if it is the intracellular content of copper that is responsible for cytotoxicity of DSF, we measured viability of DSF-treated LD U937 cells in media containing bathocuproine disulfonic acid (BCPS) that acts as a copper-specific cell impermeable chelator (12), and N-acetyl-L-cysteine (NAC), which was shown to suppress cytotoxicity of dithiocarbamates (13). Intracellular concentration of copper in these cells was assessed by direct SALD ICP MS analysis. We found that BCPS as well as NAC completely blocked the DSF-induced accumulation of copper in LD U937 cells (Fig. 5A). At the same time, these compounds resumed viability of DSFtreated LD U937 cells to standard level (Fig. 5B), and suppressed apoptosis, as documented by absence of the PARP truncation (Fig. 5C), and apoptotic cell morphology (Fig. 5D), as determined by gel electrophoresis and fluorescence microscopy, respectively. This suggests that sufficient amount of intracellular copper is an important prerequisite for induction of apoptosis of U937 cells by DSF.

Next, we compared intracellular concentrations of copper in DSF-treated myeloid leukemia cells cultured at various densities. We did not find statistically significant differences in concentrations of intracellular copper in untreated- and DMSO-treated LD and HD control cells. However, upon treatment with DSF, intracellular concentration of copper increased: $25 \mathrm{ng} / \mathrm{ml}$ DSF caused 3-fold- and $50 \mathrm{ng} / \mathrm{ml} \mathrm{DSF}$ about 4-fold increase of copper, both in LD and HD U937 cells (Fig. 6). Interestingly, when used in $100 \mathrm{ng} / \mathrm{ml}$ concentration, DSF induced a 10-fold increase of intracellular copper only 


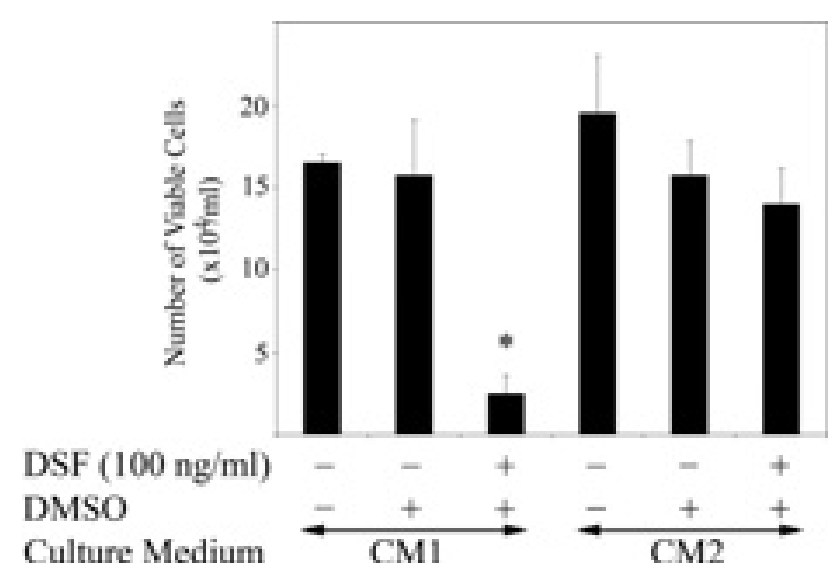

Figure 4. Medium conditioned by DSF-treated HD U937 cells does not permit sensitivity of LD U937 cells to DSF. HD U937 cells were treated with either DMSO or DSF (100 ng/ml) for $24 \mathrm{~h}$. The medium deprived of DMSO-treated cells by centrifugation served as conditioned medium CM1 (filled columns), the medium deprived of DSF-treated cells served as conditioned medium CM2. U937 cells were seeded at low density in CM1 and CM2 and treated with DSF (100 ng/ml) for $24 \mathrm{~h}$. As a control, the cells were either left untreated or treated with DMSO. The columns indicate total number of viable cells determined by eosin dye exclusion using light microscopy. Error bars indicate standard deviations. Data were obtained from three independent experiments and processed by Student's t-test. Asterisks indicates significant differences $(\mathrm{p}<0.05)$ from viability of cells in CM2.

A

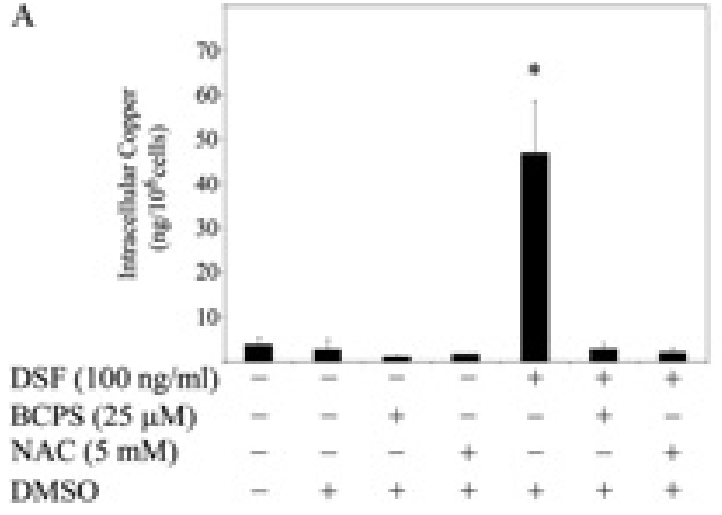

in LD but not in HD U937 cells (Fig. 6). Neither higher dose of DSF (400 ng/ml) (Fig. 6), nor extended time of treatment (24 h) (not shown) elevated the intracellular content of copper in HD U937 cells. DSF-treated HD U937 cells reached similar level of copper as LD U937 cells only when growth medium was supplemented with external $\mathrm{CuSO}_{4}$ (Fig. 6). These results document that DSF-induced accumulation of copper in U937 cells is cell density dependent.

To further confirm that intracellular content of copper affects cytotoxicity of DSF, we compared viability of HD U937 cells cultured in regular medium and in medium supplemented with $\mathrm{CuSO}_{4}$ in concentration range 70-200 nM. These cells were treated with DSF before cell viability and frequency of apoptosis were assessed. We showed earlier that addition of $\mathrm{Cu}^{2+}$ to growth medium in concentration as low as $70 \mathrm{nM}$ significantly increased intracellular level of copper in DSF-treated HD U937 cells (Fig. 6). At the same time, it significantly decreased viability of these cells, reaching only $40 \%$ of the viability of the same cells grown in the regular media (Fig. 7). In fact, lower viability of DSF-treated HD U937 cells growing in media supplemented with $\mathrm{Cu}^{2+}$ correlated with increased frequency of programmed cell death as documented by analyses of the PARP truncation and frequency of apoptotic cell morphology (Fig. 8). These results document that differential sensitivity of U937 cell
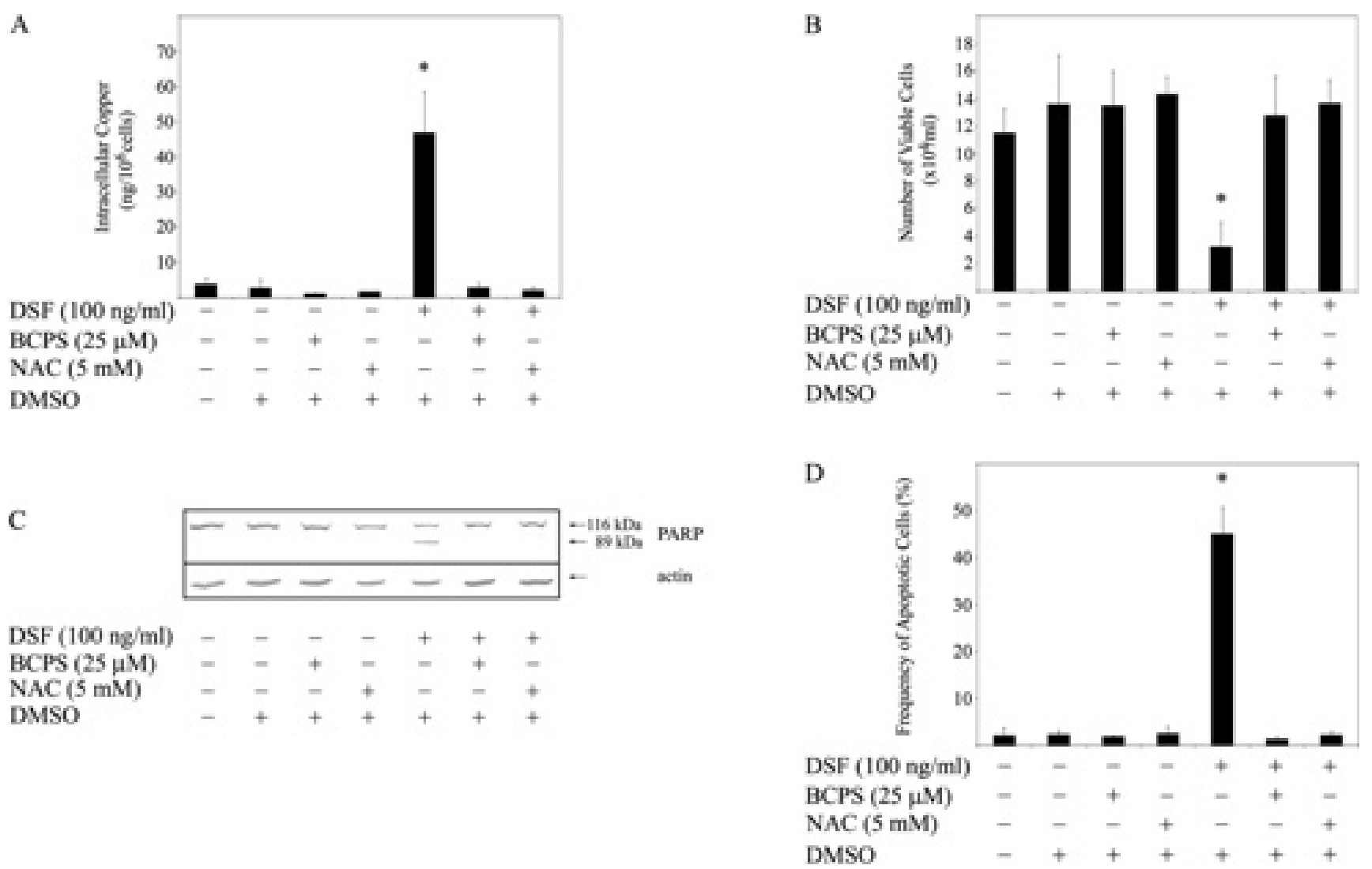

Figure 5. BCPS and NAC decrease intracellular level of copper, resume viability and suppress apoptosis of DSF-treated LD U937 cells. U937 cells were seeded at density of 50,000 cells $/ \mathrm{ml}$ and treated with DSF in the presence or absence of BCPS and NAC for $6 \mathrm{~h}$. The level of copper in harvested and lysed cells was determined by SALD ICP MS. The columns indicate the level of intracellular copper (ng) in $10^{6}$ cells (A). Viability of the same cells treated for $24 \mathrm{~h}$ was assessed by eosin dye exclusion using light microscopy. The columns represent total number of viable cells (B). The cells treated for $12 \mathrm{~h}$ were harvested and either used for SDS-PAGE and immunoblotting of protein extracts using the PARP-specific antibody (upper band) and actin-specific antibody (lower band) as a control for sample loading (C) or fixed and stained with propidium iodide and inspected by fluorescence microscopy (D). Morphology of at least 200 cells in each sample was examined. Error bars indicate standard deviations. Asterisk denotes significant difference from all other samples ( $<<0.05)$. Data were obtained from three independent experiments and processed by Student's t-test. 


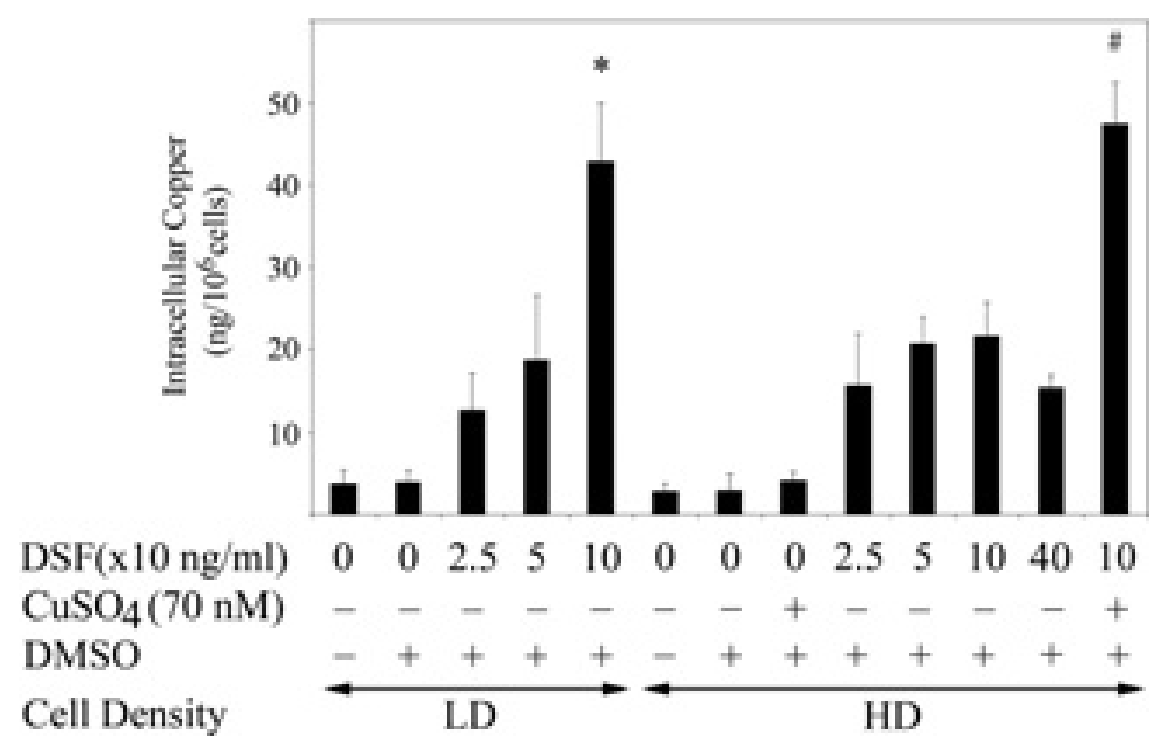

Figure 6. Intracellular content of copper increases in DSF-treated U937 cells in a cell density-dependent manner. U937 cells were seeded at densities 50,000 cells/ml (LD) and 200,000 cells/ml (HD), and treated with $\mathrm{DSF} / \mathrm{CuSO}_{4}$ at indicated concentrations for $6 \mathrm{~h}$. As a control, the cells were treated with either DMSO vehicle, DMSO in combination with $\mathrm{CuSO}_{4}$ or left untreated. The level of copper in harvested and lysed cells was determined by SALD ICP MS as described in 'Material and methods'. The columns indicate the level of copper (ng) in $10^{6}$ cells. Error bars indicate standard deviations. Data were obtained from three independent experiments and processed using Student's t-test. Asterisk indicates the significant difference from HD cells treated with DSF in concentration $100 \mathrm{ng} / \mathrm{ml}(\mathrm{p}<0.05)$, \# indicates the significant difference from HD cells treated with $\mathrm{DMSO} / \mathrm{CuSO}_{4}(\mathrm{p}<0.05)$ as determined by Student's t-test.

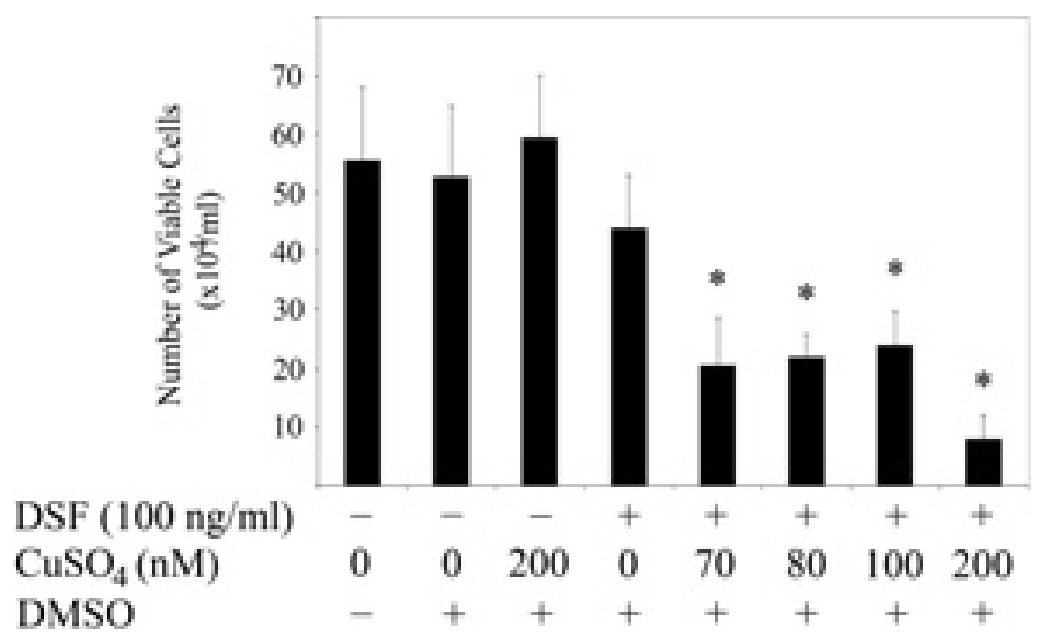

Figure 7. Copper ions enhance cytotoxic effects of DSF to HD U937 cells. U937 cells were seeded at high density (200,000 cells/ml) and treated with DSF in regular medium or in medium supplemented with $\mathrm{CuSO}_{4}$ at indicated concentrations for $24 \mathrm{~h}$. As a control, the cells were treated with DMSO in the presence or absence of $\mathrm{CuSO}_{4}$ or left untreated. Number of viable cells was assessed by eosin dye exclusion using light microscopy. Columns represent total number of viable cells, error bars show standard deviations. Data were obtained from three independent experiments and processed by Student's t-test. Asterisks indicate significant differences $(\mathrm{p}<0.05)$ from untreated-, DMSO-, DMSO/CuSO $4(200 \mathrm{nM})$ - and DMSO/DSF-treated cells.

populations growing at low and high densities to DSF results from different intracellular concentrations of the copper ions.

Since DSF-treated cells passively uptake copper from outside (16), we can expect that the media used for $24 \mathrm{~h}$ cultivation of DSF-treated and untreated cells will contain different amounts of this metal. Indeed, as determined by ICP MS analysis, concentration of copper remained in the growth media upon cultivation of DMSO-treated HD U937 cells for $24 \mathrm{~h}$ (conditioned medium 1, CM1) was signifi-cantly higher than in the growth media upon treatment of the same cells with DSF (conditioned medium 2, CM2) (151 nM vs. 83 $\mathrm{nM})$. In order to compare availabity of the copper in CM1 and CM2, we used them to feed either LD or HD U937 cells in the presence or absence of DSF. We found that both LD and HD U937 cells treated with DSF successfully used copper from CM1 to increase intracellular level of this metal to very similar extent as described earlier for these cells growing in regular unconditioned media (compare Figs. 6 and 9). However, U937 cells irrespective of their density failed to use copper from CM2 to increase intracellular level of this metal in response to DSF (Fig. 9). These results 
A

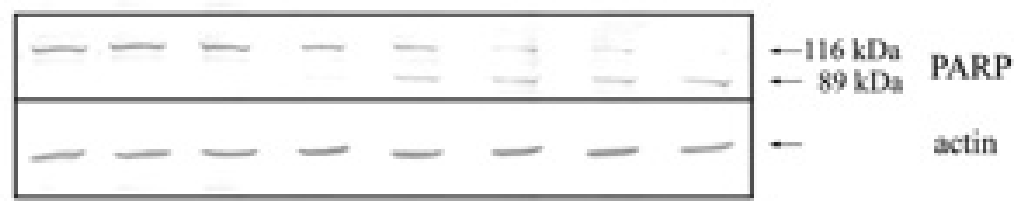

$\operatorname{DSF}(100 \mathrm{ng} / \mathrm{ml})-+-++++$

B

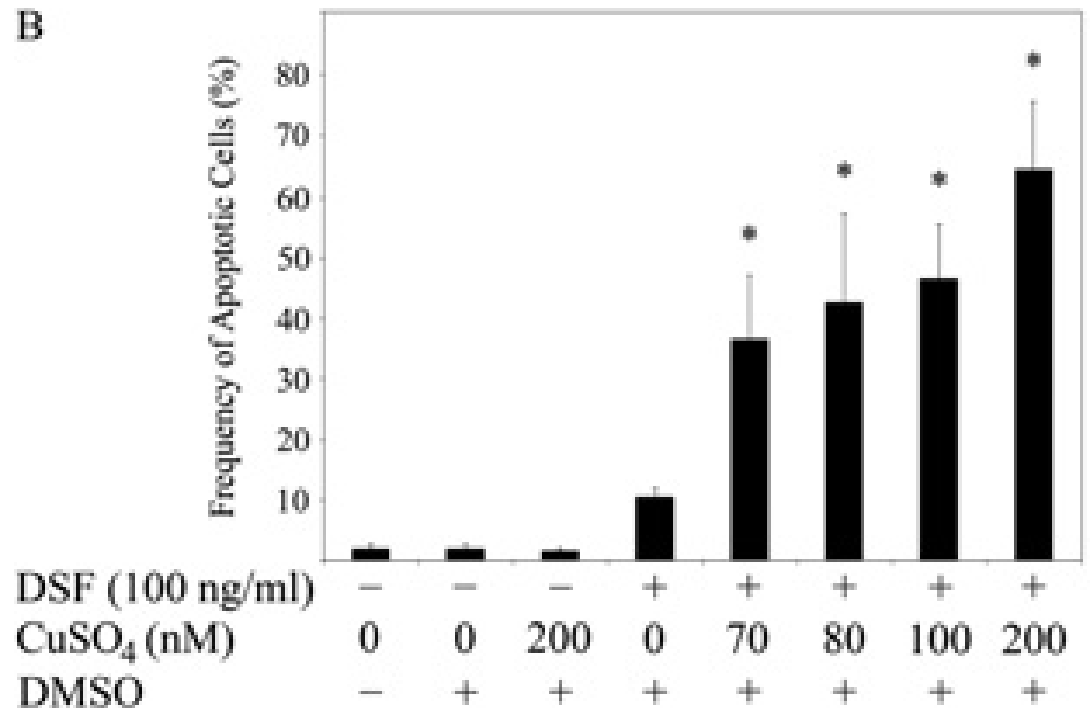

Figure 8. Copper ions enhance DSF-induced apoptosis of HD U937 cells. U937 cells were seeded at high density (200,000 cells/ml) and treated with DSF in regular medium or in medium supplemented with $\mathrm{CuSO}_{4}$ at indicated concentrations for $12 \mathrm{~h}$. As a control, the cells were treated with DMSO in the presence or absence of $\mathrm{CuSO}_{4}$ or left untreated. Protein extracts from harvested cells were resolved by SDS-PAGE and analysed by immunoblotting using the PARPspecific antibody (upper band) and actin-specific antibody (lower band) as a control for sample loading (A). Harvested cells were fixed and stained with propidium iodide. Morphology of at least 200 cells in each sample was examined by fluorescence microscopy (B). Error bars indicate standard deviations. Asterisks denote significant differences from DSF/DMSO-treated cells $(\mathrm{p}<0.05)$. Data were obtained from three independent experiments and processed by Student's t-test.

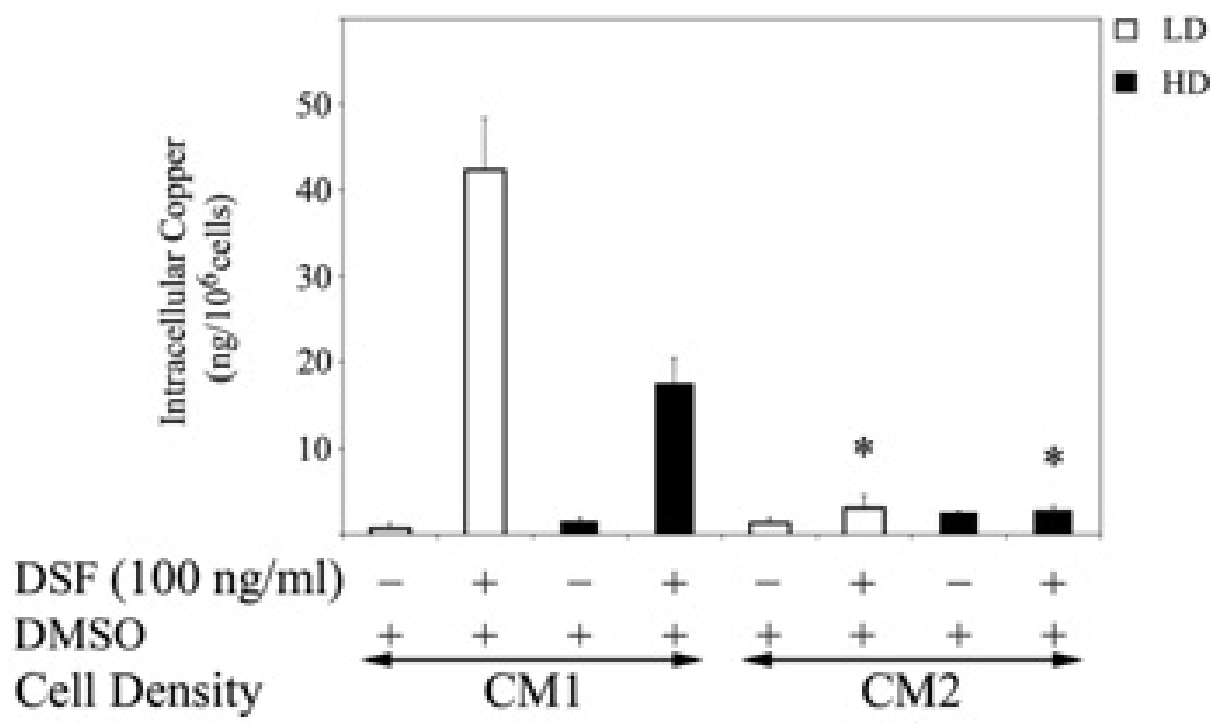

Figure 9. HD U937 cells contain lower level of intracellular copper than LD cells due to the depletion of copper supply in growth medium. HD U937 cells were treated with either DMSO or DSF for $24 \mathrm{~h}$. The medium cleared of DMSO-treated cells by centrifugation (conditioned medium CM1) and the medium cleared of DSF-treated cells (conditioned medium CM2) were used to feed either LD U937 cells (open columns) or HD U937 cells (filled columns). DSF and/or DMSO were added to CM1 and CM2 for $6 \mathrm{~h}$. The level of copper in cells was determined as described in the legend to Fig. 4. The columns indicate the level of copper (ng) in $10^{6}$ cells. Error bars indicate standard deviations. Data were obtained from three independent experiments and processed using Student's $\mathrm{t}$-test. Asterisks indicate significant differences $(\mathrm{p}<0.05)$ from DSF-treated cells in CM1. 
indicate that the DSF-treated HD U937 cells deplete the growth media of copper to the basal level, thus eliminating its further transport into the cells. The lack of intracellular copper occuring in dense cell populations then limits apoptosispromoting effects of DSF.

\section{Discussion}

Cell density limits cytotoxicity of many commonly used chemotherapeutics due to inoculum effect. This phenomenon is defined as rapid decrease of drug efficacy and its intracellular and extracellular concentrations with increasing cell density $(3,5,24)$. For example, 4 -fold increase of HL-60 cell density results in 4-fold increase of IC50 for daunorubicin (3). Similar effect was described also for vincristine (5). In contrast, cisplatin and carboplatin do not exhibit the inoculum effect, since cell density does not affect cytotoxic doseresponse curves and cellular accumulation of these drugs $(4,25)$.

DSF is increasingly appreciated in therapy of leukemia (11). In this study, we report that tumor suppressive effects of DSF on leukemic cells depend on cell density, and we describe mechanism of this phenomenon. We show that DSF can significantly limit viability of human myeloid leukemia U937 and ML-1 cells by inducing caspase-dependent programmed cell death pathways in doses $100-200 \mathrm{ng} / \mathrm{ml}$ that are safe in human plasma (26). This effect is clearly cell density-dependent because it is most prominent in cells seeded at low density $(50,000$ cells $/ \mathrm{ml})$ and disappears as cell density increases. Interestingly, this is not a regular inoculum effect since it is not suppressed by increased dose of DSF. U937 cells seeded only at 4-fold higher density became resistant to DSF in concentration exceeding the apoptosisinducing dose of DSF for LD U937 cells 16-fold. ML-1 cells responded to treatment with DSF in similar way as U937 cells. Since failure of DSF to exert its anti-cancer effects is clinically important, we focused on this phenomen in more detail. First, we confirmed that there are no significant changes in cell cycle profiles of DSF-sensitive (LD) and DSF-resistant (HD) U937. This indicates that resistance of HD U937 cells to DSF cannot be explained by general drug resistance exhibited by cells in the plateau phase of growth (9). Next, we searched for factor(s) responsible for cell density-dependent cytotoxicity of DSF on leukemic cells in growth medium, as cytotoxicity of DSF to LD U937 cells was abrogated by medium conditioned by DSF-treated HD U937 cells. We focused on the copper ions, since DSF acts as a cell permeable metal-chelator inducing growth arrest and apoptosis of various cell types by increasing intracellular concentration of this metal (12). Two lines of evidence indicate that copper ions are essential for capacity of DSF to induce apoptosis of U937 and ML1 cells growing at low densities. First, once intracellular accumulation of copper ions was blocked by BCPS, the copper-specific cell impermeable chelator (12) or by scavenger of reactive oxygen species NAC (27), viability of DSF-treated LD U937 cells was rescued and apoptosis significantly suppressed. Second, once provided with external copper ions, the DSF-resistant HD U937 cells increased intracellular content of copper and resumed capacity to undergo DSF-induced apoptosis to similar extent as LD U937 cells. This indicates that low intracellular level of copper, rather than cell density-dependent changes in expression profiles (28) and cell-cell interactions (8), is responsible for decreased toxicity of DSF for high density cell cultures.

Cells take up copper from extracellular environment, thus cell populations growing at high density will deplete the medium of this metal faster than cells growing at low density. Indeed, as determined by ICP MS, the copper concentration in medium of DSF-treated HD U937 was significantly lower than in medium of DSF-treated LD U937. In fact, we found only basal level of copper in medium used for cultivation of DSF-treated HD U937 cells (83 nM) that was no longer available for uptake by U937 cells regardless of their density. These results document that differential sensitivity of leukemic cells growing at different densities to DSF is based on availability of extracellular copper ions. The DSF-induced uptake of copper is sufficient to permit apoptosis of myeloid leukemia cells growing at low density. In contrast, the same cells growing at high density compete for limited supply of accessible extracellular copper, resulting in lower intracellular accumulation of this metal and failure to undergo apoptosis. This study shows that leukemic cells are not sensitive to DSF when intracellular concentration of copper is about $15 \mathrm{ng} /$ million cells. To permit induction of apoptosis in response to DSF, intracellular concentration of copper must reach at least $36 \mathrm{ng} /$ million cells. These data are clinically relevant with regard to the copper concentration in human plasma and large interindividual variation in WBC count in AML patients (29). Therefore, this study emphasizes the need to adjust copper dosage in DSF therapy according to the WBC count.

The lack of sensitivity of cells growing at high densities to dithiocarbamates limits use of these drugs in anti-cancer therapies. This study explains the rationale of this phenomenon and suggests a way of solving this problem: simple addition of copper significantly increases cytotoxicity of DSF to dense populations of myeloid leukemia cells that are otherwise considered to be DSF-insensitive.

\section{Acknowledgement}

This work was supported by grants MSM0021622415, MSM0021622411, MSM0021622412, of the Ministry of Education, Youth and Sports of the Czech Republic, and $301 / 09 / 1115$ and 203/09/1025 of the Czech Science Foundation.

\section{References}

1. Friedmann AM and Weinstein HJ: The role of prognostic features in the treatment of childhood acute lymphoblastic leukemia. Oncologist 5: 321-328, 2000.

2. Matthews JP, Bishop JF, Young GA, et al: Patterns of failure with increasing intensification of induction chemotherapy for acute myeloid leukaemia. Br J Haematol 113: 727-736, 2001.

3. Masquelier M and Vitols S: Drastic effect of cell density on the cytotoxicity of daunorubucin and cytosine arabinoside. Biochem Pharmacol 67: 1639-1646, 2004.

4. Takemura Y, Kobayashi H, Miyachi H, Hayashi K, Sekiguchi S and Ohnuma T: The influence of tumor cell density on cellular accumulation of doxorubicin or cisplatin in vitro. Cancer Chemother Pharmacol 27: 417-422, 1991. 
5. Kobayashi H, Takemure Y, Holland JS and Ohnuma T: Vincristine saturation of cellular binding sites and its cytotoxic activity in human lymphoblastic leukemia cells. Biochem Pharm 55: 1229-1234, 1998.

6. Brandt S, Heller H, Schuster KD and Grote J: Tamoxifen induces suppression of cell viability and apoptosis in the human hepatoblastoma cell line HepG2 via down-regulation of telomerase activity. Liver Int 24: 46-54, 2004.

7. Jang SH, Wientjes MG and Au JL: Determinants of paclitaxel uptake, accumulation and retention in solid tumors. Invest New Drugs 19: 113-123, 2001.

8. Caceres-Cortes JR, Alvarado-Moreno JA, Waga K, RangelCorona $\mathrm{R}$, et al: Implication of tyrosine kinase receptor and steel factor in cell density-dependent growth in cervical cancers and leukemias. Cancer Res 61: 6281-6289, 2001.

9. Valkov NI, Gump JL, Engel R and Sullivan DM: Cell densitydependent VP-16 sensitivity of leukaemic cells is accompanied by the translocation of topoisomerase IIalpha from the nucleus to the cytoplasm. Br J Haematol 108: 331-345, 2000.

10. Chick J: Safety issues concerning the use of disulfiram in treating alcohol dependence. Drug Saf 20: 427-435, 1999.

11. Wickstrom M, Danielsson K, Rickardson L, Gullbo J, Nygren P, Isaksson A, Larsson $\mathrm{R}$ and Lovborg $\mathrm{H}$ : Pharmacological profiling of disulfiram using human tumor cell lines and human tumor cells from patients. Biochem Pharmacol 73: 25-33, 2007.

12. Brar SS, Grigg C, Wilson KS, et al: Disulfiram inhibits activating transcription factor/cyclic AMP-responsive element binding protein and human melanoma growth in a metaldependent manner in vitro, in mice and in a patient with metastatic disease. Mol Cancer Ther 3: 1049-1060, 2004.

13. Cen D, Gonzalez RI, Buckmeier JA, Kahlon RS, Tohidian NB and Meyskens FL Jr: Disulfiram induces apoptosis in human melanoma cells: a redox-related process. Mol Cancer Ther 1: 197-204, 2002.

14. Chen D, Cui QC, Yang H and Dou QP: Disulfiram, a clinically used anti-alcoholism drug and copper-binding agent, induces apoptotic cell death in breast cancer cultures and xenografts via inhibition of the proteasome activity. Cancer Res 66: 10425-10433, 2006.

15. Burkitt MJ, Bishop HS, Milne L, Tsang SY, Provan GJ, Nobel CS, Orrenius S and Slater AF: Dithiocarbamate toxicity toward thymocytes involves their copper-catalyzed conversion to thiuram disulfides, which oxidize glutathione in a redox cycle without the release of reactive oxygen species. Arch Biochem Biophys 353: 73-84, 1998.

16. Cen D, Brayton D, Shahandeh B, Meyskens FL Jr and Farmer PJ: Disulfiram facilitates intracellular $\mathrm{Cu}$ uptake and induces apoptosis in human melanoma cells. J Med Chem 47: 6914-6920, 2004.

17. Chen SH, Liu SH, Liang YC, Lin JK and Lin-Shiau SY: Death signaling pathway induced by pyrrolidine dithiocarbamate$\mathrm{Cu}(2+)$ complex in the cultured rat cortical astrocytes. Glia 31: 249-261, 2000
18. Chen D, Peng F, Cui QC, Daniel KG, Orlu S, Liu J and Dou QP: Inhibition of prostate cancer cellular proteasome activity by a pyrrolidine dithiocarbamate-copper complex is associated with suppression of proliferation and induction of apoptosis. Front Biosci 10: 2932-2939, 2005.

19. Chen J, Du C, Kang J and Wang $\mathrm{J}: \mathrm{Cu}^{2+}$ is required for pyrrolidine dithiocarbamate to inhibit histone acetylation and induce human leukemia cell apoptosis. Chem Biol Interact 171: 26-36, 2008

20. Erl W, Weber C and Hansson GK: Pyrrolidine dithiocarbamateinduced apoptosis depends on cell type, density, and the presence of $\mathrm{Cu}(2+)$ and $\mathrm{Zn}(2+)$. Am J Physiol Cell Physiol 278: C1116-C1125, 2000.

21. Watanabe T, Yoshizumi M, Akishita M, et al: Induction of nuclear orphan receptor NGFI-B gene and apoptosis in rat vascular smooth muscle cells treated with pyrrolidinedithiocarbamate. Arterioscler Thromb Vasc Biol 21: 1738-1744, 2001.

22. Vindelov LL: Flow microfluorometric analysis of nuclear DNA in cells from solid tumors and cell suspensions. A new method for rapid isolation and staining of nuclei. Virchows Arch B Cell Pathol 24: 227-242, 1977.

23. Pes O, Jungova P, Vyhnanek R, Vaculovic T, Kanicky V and Preisler J: Off-line coupling of capillary electrophoresis to substrate-assisted laser desorption inductively coupled plasma mass spectrometry. Anal Chem 80: 8725-8732, 2008.

24. Slapak CA, Lecerf JM, Daniel JC and Levy SB: Energydependent accumulation of daunorubicin into subcellular compartments of human leukemia cells and cytoplasts. J Biol Chem 267: 10638-10644, 1992.

25. Ohnuma T, Arkin H and Holland JF: Effects of cell density on drug-induced cell kill kinetics in vitro (inoculum effect). Br J Cancer 54: 415-421, 1986.

26. Sauna ZE, Shukla S and Ambudkar SV: Disulfiram, an old drug with new potential therapeutic uses for human cancers and fungal infections. Mol Biosyst 1: 127-134, 2005.

27. Schwarze CP, Neu S, Beck J, Mavridou K, Ranke MB and Binder G: Influence of IGF-I and cell density on MDR 1 expression in the T-lymphoblastoid cell line CCRF-CEM. Horm Res 52: 192-199, 1999.

28. Akca T, Canbaz H, Tataroglu C, et al: The effect of N-acetylcysteine on pulmonary lipid peroxidation and tissue damage. $\mathrm{J}$ Surg Res 129: 38-45, 2005.

29. Venelinov TI, Davies IM and Beattie JH: Dialysis-Chelex method for determination of exchangeable copper in human plasma. Anal Bioanal Chem 379: 777-780, 2004. 